\title{
Analysis of Variable Parameters of Prediction Models
}

\author{
Monika KUBZOVA ${ }^{1}$, Vit KRIVY ${ }^{1}$, Martin KREJSA ${ }^{2}$, Katerina KREISLOVA ${ }^{3}$ \\ ${ }^{1}$ Department of Structures, Faculty of Civil Engineering, VSB - Technical University of Ostrava, \\ Ludvika Podeste 1875/17, Ostrava - Poruba, Czech Republic \\ ${ }^{2}$ Department of Structural Mechanics, Faculty of Civil Engineering, VSB - Technical University of Ostrava, \\ Ludvika Podeste 1875/17, Ostrava - Poruba, Czech Republic \\ ${ }^{3}$ SVUOM Ltd., U Mestanskeho Pivovaru 934/4, Prague 7, Czech Republic \\ monika.kubzova@vsb.cz, vit.krivy@vssb.cz, martin.krejsa@vsb.cz, kreislova@,svuom.cz
}

DOI: $10.31490 /$ tces-2018-0010

\begin{abstract}
The article deals with the calculation of corrosion losses of weathering steels with doseresponse functions. The environmental parameters of atmospheric corrosion incoming the dose-response functions are analysed by statistic and probabilistic methods. Between main environmental parameters belong temperature $T$, concentration of sulphur dioxide, relative air humidity $\mathrm{RH}$, and deposition of chloride. Long-term measurements of environmental characteristics at atmospheric test sites were used for the analysis. All the environmental parameters incoming the dose-response functions are considered random variables represented by corresponding histogram. Using the probabilistic analysis it is possible to predict the expected range of corrosion rates and to analyse the impact of particular environmental characteristic on corrosion process.
\end{abstract}

\section{Keywords}

Weathering steel; atmospheric corrosion; prediction model; atmospheric parameters; probabilistic approach.

\section{Introduction}

Between main atmospheric corrosion factors belong relative air humidity; air temperature; deposition rates of corrosion stimulators (sulphur dioxide and chlorides); the amount of dust particles in air; amount of rainfall; $\mathrm{pH}$ of rainfall, see $[1,2]$. Surface location within the steel structure has also significant influence on corrosion behaviour and development of corrosion products [3, 4].

For the design of structures located in the outdoor environment is suitable to use steel with improved resistance to atmospheric corrosion, so called weathering steel. These steels belong to low alloy steel contain up to 2 wt. \% of alloying elements such as $\mathrm{Cu}, \mathrm{Cr}, \mathrm{Ni}$ and $\mathrm{P}$. These elements positively affect the corrosion properties of the steel and its corrosion behaviour in outdoor environment [5]. At the surface of the steel a protective layer of corrosion products, so called patina, is formed under suitable exposure conditions [6]. A sufficient patina layer is usually formed after 5 to 8 years of direct exposure, but in case of partially protected surfaces, the development of fully protective patina is slower.

Corrosion rates after one year of exposure $r_{\text {corr }}$ are the basic characteristics of corrosion behaviour of weathering steels in a specific environment. Corrosion rates can be directly measured using standard specimens according to EN ISO 9223 [7] or suitable prediction models taking into account the environmental characteristics of the locality may be used to predict the corrosion behaviour.

Environmental parameters entering into prediction models are naturally random variables, so it is appropriate to use probability methods when applying prediction models.

\section{Prediction of corrosion losses}

It is possible to divide the prediction models into two groups - prediction models for estimating corrosion rate (corrosion loss) after the first year of exposure and prediction models for estimating corrosion loss after longterm exposure of the structure.

\subsection{Long-term corrosion losses}

Long-term exposure of weathering steel leads, with extended exposure duration, to gradual deceleration of corrosion loss of material on the surface of the structure. The basic input variable for prediction of long-term corrosion loss is the corrosion rate in the first year of exposure of the steel $r_{\text {corr }}$. The value of long-term 
corrosion loss can be determined in compliance with EN ISO 9224 [8] according to the formula:

$$
D=r_{\text {corr }} \cdot t^{b}
$$

where $D$ is corrosion depth of corrosion $\left[\mathrm{g} / \mathrm{m}^{2}\right.$ or $\left.\mu \mathrm{m}\right]$; $t$ is exposure time [years]; $r_{\text {corr }}$ is corrosion rate in the first year of exposure $\left[\mathrm{g} /\left(\mathrm{m}^{2} \cdot \mathrm{y}\right), \mu \mathrm{m} / \mathrm{y}\right]$ and $b$ is coefficient of time dependence specific for combination iron-environment (usually less than 1).

The input value of corrosion rate (corrosion loss) after one year of exposure can be determined in two ways: using atmospheric corrosion tests, but it is quite time consuming, or using analytical prediction equations, so called the doseresponse functions. The second method is the most commonly applied. Analytical functions were derived from the statistical processing of a large set of corrosion tests for individual type of steel [7, 9, 10]. The input parameters of dose-response function are annual environmental parameters, which are naturally random variable. It is appropriate to use probability methods when applying prediction models.

\subsection{Corrosion losses in the first year of exposure of the steel}

In this article are shown three selected dose-response functions for calculating of corrosion losses in the first year of exposure.

Dose-response function according EN ISO 9223 [7], which is derived from large sets of experimentally tests of atmospheric corrosion, is in the following form:

$$
\begin{gathered}
r_{\text {corr }}=1,77 \cdot P_{d}^{0,52} \cdot e^{(0,02 \cdot R H)} \cdot e^{f_{s t}}+0,102 \cdot S_{d}^{0,62} \\
\cdot e^{(0,033 \cdot R H+0,04 \cdot T)}
\end{gathered}
$$

Dose-response function derived from program UN/ECE ICP [9] in years 1987 - 1995 is in the following form:

$$
r_{\text {corr }}=34 \cdot P_{d}^{0,33} \cdot e^{0,02 \cdot R H} \cdot e^{f_{s t}}
$$

Finally, dose-response function derived from program Multi-Assess [9] in years $1970-2005$ is in the following form:

$$
\begin{gathered}
r_{\text {corr }}=29,1+\left\{21,7+1,39 \cdot P_{d}^{0,6} \cdot R H_{60} \cdot e^{f_{\text {st }}}+1,29 \cdot R A I N\right. \\
\left.\left[H^{+}\right]+0,593 \cdot P M_{10}\right\}
\end{gathered}
$$

where $f_{\text {st }}$ function is calculated separately according to annual temperature; $P_{\mathrm{d}}$ is the average annual deposition rate of $\mathrm{SO}_{2}\left[\mathrm{mg} /\left(\mathrm{m}^{2} \cdot \mathrm{d}\right)\right] ; S_{\mathrm{d}}$ is the average annual deposition rate of $\mathrm{Cl}^{-}\left[\mathrm{mg} /\left(\mathrm{m}^{2} \cdot \mathrm{d}\right)\right]$; RAIN is the average annual rainfall [mm]; $R H_{60}$ or $R H$ is the average annual relative humidity $[\%] ; H^{+}$is hydrogen ion concentration in rainfall $[\mathrm{mg} / \mathrm{l}]$ and $P M_{10}$ is the average annual concentration of dusty deposits (max. diameter $10 \mu \mathrm{m})\left[\mu \mathrm{g} / \mathrm{m}^{3}\right]$.

\section{Long-term monitored environmental parameters}

Mentioned prediction model used annual average values of environmental parameters. These values can be obtained from online databases, e.g. databases of the Czech Hydrometeorological Institutes of by longterm measurements. In Kopisty locality (Czech Republic) were monitored long-term climatic parameters from 1969, see Figure 1. This locality can be classified as urban environment with corrosivity category C3 [7].

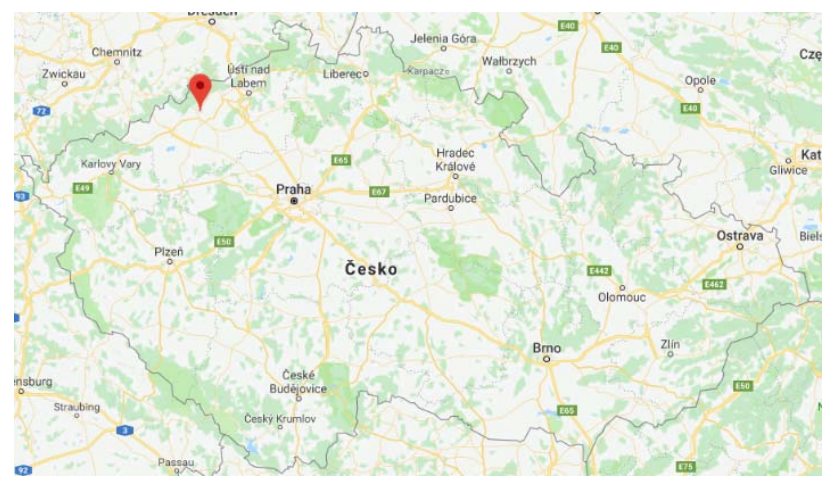

Fig. 1: Locations of tested urban environment Kopisty locality (Czech Republic)

Statistical analysis and creation of histogram of annual humidity for locality Kopisty test site are shown in this article. Average annual values of humidity are shown in Figure 2.

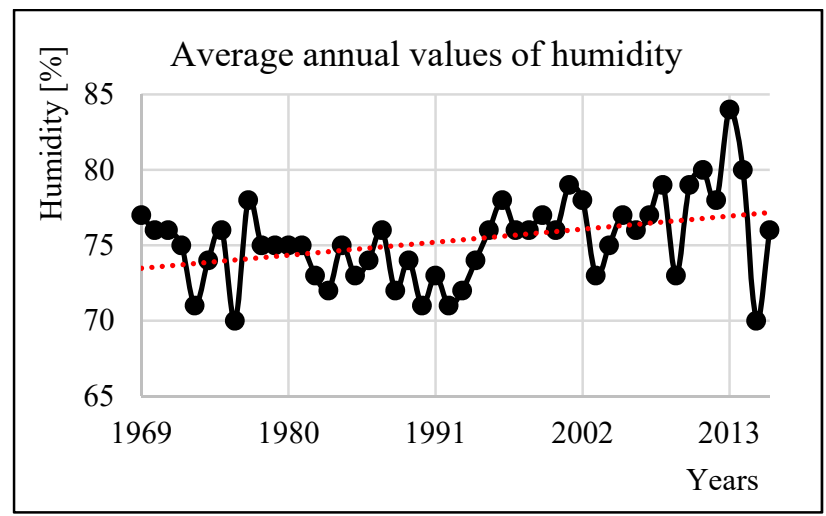

Fig. 2: Average annual values of humidity of Kopisty locality

To determine the expected range of the average annual values of humidity that will correspond to the end-date of the data series (year 2016). A statistical analysis of the measured data has to be carried out taking into account their random nature and the rising trend of humidity. For the set of data a $95 \%$ predictive interval was determined to define the area where $95 \%$ of the measured results are situated. By regression analysis of the data, the mean value of the average annual temperature is determined for 2016, whereas the 95\% boundary curve of the prediction interval allows for the determination of $2.5 \%$ and $97.5 \%$ quantile of the distribution 
respectively. From the above statistical parameters it is possible to determine the standard deviation of the normal distribution of the probability density of the monitored quantity. The mean value and the standard deviation (st. dev.) are the main parameters for construction on the normal probability density distribution. If there is made probability distribution of the entire dataset (not only from extrapolation for final year of the data series, i.e. year 2016), the mean value would not reflect the time trend of the change of the monitored variable and could influence negatively the resulting estimation of corrosion loss by means of prediction models (Figure 3). Created histogram is shown in Figure 4.

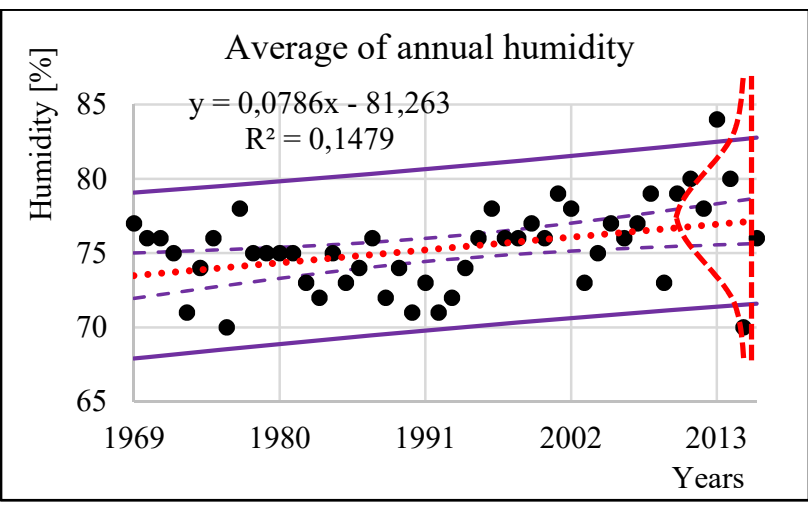

Fig. 3: Statistical analysis of average values of annual humidity for Kopisty locality - regression analysis and prediction interval

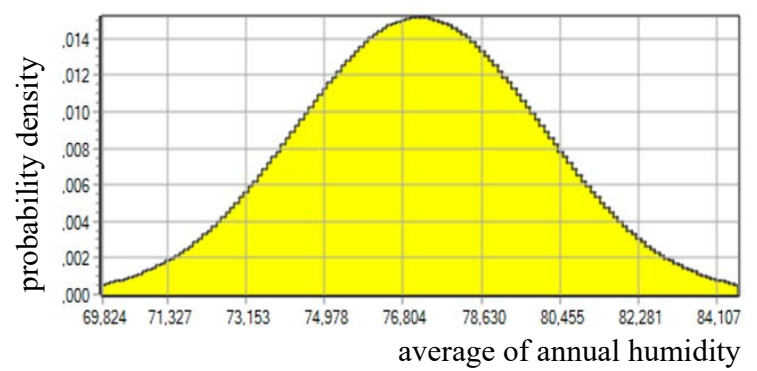

Fig. 4: Statistical analysis of humidity for Kopisty locality- regression analysis and prediction interval

\section{Probabilistic calculation of prediction model}

Regression analysis and predictive intervals have been calculated for all necessary environmental parameters, the course of which has changed significantly over the last decades. Each random variable was assigned to the corresponding probability density. Probability analysis assumes a normal distribution of the observed climatic variables. In order to eliminate negative values, some environmental parameters assume a log-normal probability distribution. In addition, the created probability density functions are cut off in the value $\pm 3 \sigma$ [11]. The characteristics of each distribution of randomly variable environmental parameters are given in Table 1.
The environmental characteristics with corresponding probability density were used as the input variables for the calculation of histograms of corrosion loss $r_{\text {corr }}$ after one year of exposure.

Tab.1: Basic characteristics of probability distribution functions of environmental parameters for Kopisty locality

\begin{tabular}{|c|c|c|c|}
\hline variable & distribution & mean value $m_{\mathrm{x}}$ & st. dev. $S_{\mathrm{x}}$ \\
\hline $\boldsymbol{T}\left[{ }^{\circ} \mathrm{C}\right]$ & normal & 9.71 & 0.65 \\
\hline $\boldsymbol{R H}[\%]$ & normal & 77.23 & 2.74 \\
\hline $\boldsymbol{R A I N}[\mathrm{mm}]$ & normal & 447.64 & 116.63 \\
\hline $\mathbf{p H}[-]$ & normal & 5.81 & 0.57 \\
\hline $\mathbf{S O}_{2}\left[\mathrm{mg} \cdot \mathrm{m}^{-2} \cdot \mathrm{d}^{-1}\right]$ & normal & 12.64 & 3.52 \\
\hline $\boldsymbol{P M}_{\mathbf{1 0}}\left[\mathrm{mg} \cdot \mathrm{m}^{-2} \cdot \mathrm{d}^{-1}\right]$ & log-normal & 21.95 & 7.49 \\
\hline $\mathbf{C l}^{-}\left[\mathrm{mg} \cdot \mathrm{m}^{-2} \cdot \mathrm{d}^{-1}\right]$ & normal & 1.08 & 0.33 \\
\hline
\end{tabular}

The ProbCalc software was used to determine the corrosion loss probability density for selected prediction models according to EN ISO 9223, UN/ECE ICP and Multi-Assess program. The obtained mean corrosion loss values $r_{\text {corr }}$ after one year of exposure including standard deviations $S_{\mathrm{x}}$ and coefficients of variation $V_{\mathrm{x}}$ are given in Table 2 . Obtained probability density of corrosion loss $r_{\text {corr }}$ after one year of exposure for locality Kopisty is shown in Figure 5 to Figure 7.

Tab.2: Basic characteristics of obtained probability density functions of corrosion losses $r_{\text {corr }}[\mu \mathrm{m}]$ after one year of exposure for locality Kopisty

\begin{tabular}{|c|c|c|c|}
\hline dose-response function & mean value $m_{\mathrm{x}}$ & st. dev. $S_{\mathrm{x}}$ & coeff. of. var $V_{\mathrm{x}}$ \\
\hline ISO 9223 & 31.68 & 4.87 & 0.15 \\
\hline UN/ECE ICP & 45.52 & 4.93 & 0.11 \\
\hline Multi-Assess & 58.33 & 10.65 & 0.18 \\
\hline
\end{tabular}

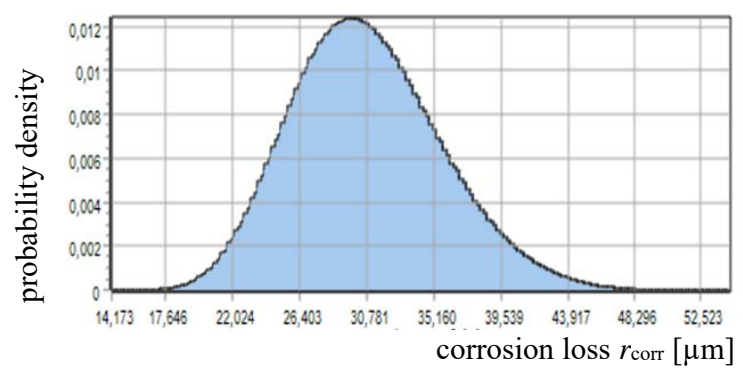

Fig. 5: Probability density of corrosion loss $r_{\text {corr }}[\mu \mathrm{m}]$ calculated according to ISO 9223 for locality Kopisty

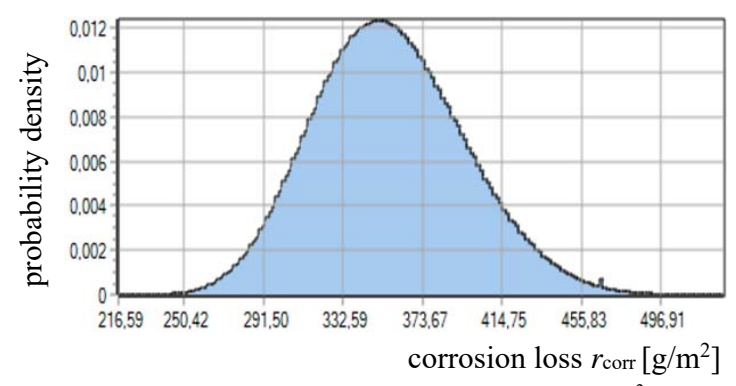

Fig. 6: Probability density of corrosion loss $r_{\text {corr }}\left[\mathrm{g} / \mathrm{m}^{2}\right]$ calculated according to program UN/ECE ICP for locality Kopisty 


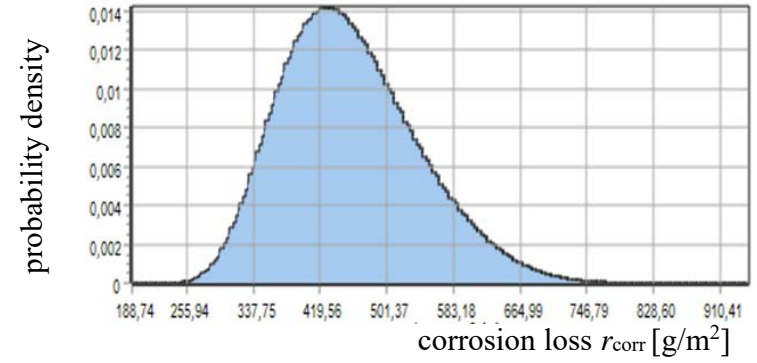

Fig. 7: Probability density of corrosion loss $r_{\text {corr }}\left[\mathrm{g} / \mathrm{m}^{2}\right]$ calculated according to program Multi-Assess for locality Kopisty

\section{Discussion}

The lowest values of corrosion losses $r_{\text {corr }}$ of weathering steel were determined by equation according to EN ISO 9223; the highest values were predicted according formula from the Multi-Asses program. The prediction models according to UN/ECE ICP and Multi-Assess seem to be too conservative.

Corrosion loss in value 21.40 was measured in real atmospheric tests in Kopisty locality during 2008 and 2009 years. This corrosion loss is influenced by decrease of concentration of sulphur dioxide. Obtained corrosion loss from real tests is lower than the values obtained from prediction models with real environmental parameters. To determine the most suitable model for prediction of weathering steel corrosion loss, analysis that is more detailed is needed. It should be based on comparing more atmospheric test results with corresponding prediction models. The values of the variation coefficient $V_{x}$ of the predicted corrosion loss histograms are within the range from 0.11 to 0.18 . The variability of predicted corrosion losses $r_{\text {corr }}$ is therefore relatively high, and it is inappropriate to use only one value (e.g. the mean value $m_{\mathrm{x}}$ ) for an accurate description of the expected corrosion loss. Probabilistic expression of the predicted corrosion loss is much more accurate.

\section{Conclusions}

Apposite prediction model of corrosion losses for the required design service life of the weathering steel structure is one of the basic presumptions for reliable dimensioning of structural elements. In the practical design of structures, predicted corrosion losses are usually replaced by a reasonable corrosion allowance to the thickness of structural elements. The expected corrosion loss after one year of exposure $r_{\text {corr }}$ is the basic input variable incoming the long-term prediction models of corrosion development on weathering steel. The $r_{\text {corr }}$ value is dependent on the random variable characteristics of the outdoor environment, and this value is therefore also a random variable. Some of the environmental parameters that affect corrosion processes show significant time trends. This fact has to be taken into account when analysing the inputs into the probabilistic prediction model.

\section{Acknowledgements}

This paper has been achieved with the financial support of the Ministry of Education, specifically by the Student Research Grant Competition of the Technical University of Ostrava under identification number SP2018/103 and part of this research has been achieved with support of project under identification number MSMT 8X17039.

\section{References}

[1] MORCILLO, M. et al. 2013. Atmospheric corrosion data of weathering steels. A review. Corrosion Science, 77, 6-24.

[2] LEYGRAF, CH. et al. 2016. Atmospheric Corrosion. Hoboken, NJ, USA: John Wiley \& Sons.

[3] KRIVY, V. et al. 2016. Development and failures of corrosion layers on typical surfaces of weathering steel bridges. Engineering Failure Analysis, 69, pp. 147- 160 .

[4] KRIVY, V. et al. 2017. Characterization of corrosion products on weathering steel bridges influenced by chloride deposition. Steels, vol. 7, no. 9.

[5] MORCILLO, M. et al. 2014. Weathering steels: From empirical development to scientific design. A review. Corrosion Science, 83, 6-31.

[6] ALBRECHT, P., HALL, TT. 2003. Atmospheric corrosion resistance of structural steels, Journal of materials in civil engineering, 15(1), 2-24.

[7] EN ISO 9223:2012, Corrosion of steels and alloys Corrosivity of atmospheres - Classification, determination and estimation.

[8] EN ISO 9224:2012, Corrosion of steels and alloys Corrosivity of atmospheres - Guiding values for the corrosivity categories.

[9] KREISLOVA, K. et al. 2017. Atmospheric corrosion models. Corrosion and corrosion protection, 61, 5966.

[10] Multi-Assess Final Report, http://www.corrinstitute.se/multi-assess/web/page.aspx. (Accessed 10 Feb 2017).

[11] MAREK, P. et al. Simulation-based reliability assessment for structural engineers. CCR Press, Boca-Raton, USA, 1996.

\section{About Authors}

Monika Kubzova was born in Bilovec, Czech Rebulic. She received her M.Sc. from VSB - Technical University of Ostrava, Faculty of Civil Engineering in 2016. Her research interests include corrosion processes on the surface of weathering steel influenced by deposition of chlorides. 
Vit Krivy interests in corrosion processes on the surface of weathering steel influenced by deposition of chlorides; design of steel structures.

Martin Krejsa interests in probabilistic calculation, DOProC Method; statistical analysis.

Katerina Kreislova interests in analysis of corrosion products and monitoring of environmental data. 